\section{Barpressing in the presence of free food as a function of food deprivation*}

\author{
ROBERT D. TARTE and RON L. SNYDER \\ University of Nevada, Las Vegas, Nev. 89109
}

Twenty-eight rats were divided into seven groups of four rats each. They were food deprived for $0,12,24,36,48,72$, and $92 \mathrm{~h}$ after pressing a bar for food for six daily 1-h sessions. After deprivation times had elapsed, Ss were placed in operant chambers and confronted with a choice between barpressing and taking food from a dish containing 300 pellets. Results showed a significant linear trend. In general, the longer that rats were deprived of food, the more they preferred to press the bar for food over taking it freely from a dish.

Havelka (1956) found that rats would prefer to run a long maze alley where a food location was changed on each trial rather than to take a shorter route to a fixed food location. Jensen (1963) demonstrated that rats would continue to press a bar for over $50 \%$ of their food when a dish filled with the same kind of food was put into their chambers if they had previously made at least 640 barpress responses. Ss with many responses $(1,280)$ before the choice pressed the bar for $75 \%$ of their food during the experimental session. Jensen proposed that the operant had an intrinsic appeal to rats. Recently, Neuringer (1969) showed that pigeons would learn to peck a disk for food reward even when the same kind of food was present in a dish in the chambers. Carder \& Berkowitz (1970) reported that rats which had pressed a bar for food on six daily 1-h sessions preferred to press the bar when given a choice during the seventh session, and concluded that a generalized preference for earned food existed in rats. These results confirmed the existence of a response phenomenon not accounted for by any "least effort" theory. Clearly, the operant in each case involved greater energy output than did consumption of the free food.

The training procedures for both Jensen's (1963) and Carder \& Berkowitz's (1970) studies maintained approximately $23 \cdot \mathrm{h}$ food-deprivation schedules. Ss were also $23 \mathrm{~h}$ deprived for the choice days, but they were allowed to press the bar 25 and 50 times before the free food was put into the chambers in the Carder and Berkowitz study. Jensen allowed 40 prechoice responses during his experimental periods. Therefore, the Ss in these studies were not food deprived before the actual choice periods to the same extent as they were during the training sessions. The

*This research was supported by a grant from the University of Nevada to the first author. purpose of the present investigation was to determine how the preference for barpressing might vary with hours of food deprivation.

\section{METHOD}

Twenty-eight experimentally naive adult female albino rats were allowed to consume $0.045 \mathrm{~g}$ Noyes food pellets from a dish containing 300 pellets placed in an operant chamber for 1 -h sessions on 3 consecutive days. The rats were $23 \mathrm{~h}$ food deprived between sessions throughout the training procedure. Ss were trained to press a bar for pellets on the fourth day. One press would release one pellet into a dish which was identical to the one which was filled with pellets on the first three sessions. The earned food dish was located approximately $5 \mathrm{~cm}$ to the left of the bar, and the free food dish was placed against the opposite end of the box. Both of these dishes were secured to the chamber floor as permanent fixtures throughout the procedure. The free food dish was empty during barpress training and practice. Ss operated the bar for food on six daily 1-h sessions. The mean total number of barpresses per animal for the six sessions was 1,840 .

After the sixth barpressing session, Ss were assigned randomly to seven groups of four Ss each. The seven groups were to be deprived of food for increasing amounts of time prior to the experimental session when they would have the choice of eating pellets from the "free" dish or pressing the

Table 1

Percentage of Barpressing as a Function of Hours of Food Deprivation in 28 Rats

\begin{tabular}{|c|c|c|c|c|c|c|}
\hline \multirow[b]{2}{*}{ Group } & \multirow{2}{*}{$\begin{array}{c}\text { Hours of Food } \\
\text { Deprivation }\end{array}$} & \multicolumn{4}{|c|}{ Percentages of Pellets Taken by Barpressing } & \multirow[b]{2}{*}{ Mean } \\
\hline & & & Individual & Animals & & \\
\hline 1 & 0 & 5 & 18 & 19 & 95 & 29.55 \\
\hline 2 & 12 & 0 & 6 & 10 & 76 & 23.00 \\
\hline 3 & 24 & 38 & 58 & 88 & 100 & 71.00 \\
\hline 4 & 36 & 45 & 77 & 80 & 83 & 71.25 \\
\hline 5 & 48 & 71 & 76 & 89 & 95 & 82.75 \\
\hline 6 & 72 & 83 & 91 & 100 & 100 & 93.50 \\
\hline 7 & 92 & 55 & 88 & 92 & 97 & 83.00 \\
\hline
\end{tabular}

bar. Group 1 was given rat chow in their home cages after the sixth bar training session so as to be $0 \mathrm{~h}$ deprived. Group 2 was deprived of food for $12 \mathrm{~h}$ prior to the experimental session. The total elapsed times between the last training session and 7 were deprived for $36,48,72$, and $92 \mathrm{~h}$ respectively, before the experimental session. Thetotal elapsed times between the last training session and the experimental sessions were $24 \mathrm{~h}$ for Groups 1,2 , and 3 , and $48 \mathrm{~h}$ for Groups 4 and 5. Groups 6 and 7 were run 72 and $92 \mathrm{~h}$ after the last training session. When the deprivation times had elapsed, Ss were placed in the chambers and confronted with the free food dish filled with 300 pellets. The bar was operable but no prechoice barpresses were allowed. Ss remained in the chambers for $1 \mathrm{~h}$. During this time, barpresses were automatically recorded; the number of free food pellets consumed was obtained by postsession counting of those remaining in the dish. The number of pellets consumed via barpressing was divided by the total number of pellets consumed from both dishes to obtain the percentage of times Ss preferred to press the bar for food. Only one experimental session was carried out for each group.

\section{RESULTS}

Percentages of bar preference are recorded in Table 1 . A positive trend correlating deprivation times and bar preference was observed. A test for trend using orthogonal polynomials from Winer (1962) showed a significant linear trend $(F=19.40$, $\mathrm{p}<.001)$. Clearly, animals not deprived of food responded at lower rates than those deprived $24 \mathrm{~h}$ or longer. Analysis of variance indicated a significant treatment effect $(F=4.29$, $\mathrm{df}=6 / 21, \mathrm{p}<.01)$, and the Newman-Keuls test for ordered differences showed significant $(p<.01)$ differences between Groups 1 and 5,1 and 6,1 and 7 , and 2 and 5 . DISCUSSION

A notable feature of the results is the wide variability of barpressing preference percentages within the groups. Group 1 ranged from 5\% to $95 \%$ and Group 2 varied between 0\% 
and $76 \%$. In the two groups which were deprived for the longest periods however, all but one $S$ appeared almost "stimulus bound" to the bar. That is, during the choice sessions they spent almost the entire hour in responding. They ate the pellets very slowly and did not move about the chamber. The small number of pellets taken from the free food dish was invariably eaten at the beginning of the choice session by $S s$ in these groups.

Some possible secondary reinforcements associated with the barpress were (1) motor activity at the bar, (2) auditory feedback from the microswitch, and (3) auditory/visual feedback from the pellet dropping into the dish. Neuringer (1969) controlled for these factors in his experiment with pigeons by placing a Plexiglas cover over the feeder so that they could see but not eat the grain released by disk pecking. Since the pecking response decreased markedly after the feeder was covered, the rate of response must have been primarily a function of the availability of the earned food itself. The possibility that Ss simply preferred pellets delivered one at a time rather than massed in a dish was denied by Carder \& Berkowitz (1969). They trained a rat to eat pellets delivered one at a time at the same rate as another rat was responding for pellets. A dish filled with pellets was then placed in the chamber. The rat left the single pellet dispenser and consumed the remainder of its food from the dish. Since secondary reinforcements did not vary between groups in this experiment, they were not considered as independent variables. The differences observed between groups indicate that food deprivation is related to the barpressing preference in some functional way. The variables influencing this relationship are not apparent.

\section{REFERENCES}

CARDER, B., \& BERKOWITZ, K. Preference for earned food in relation to free food. Science, 1970, 167 , $1273-1274$.

HAVELKA, J. Problem seeking behavior in rats. Canadian Journal of Psychology, 1956, 10, 91-97.

JENSEN, G, D Preference for bar pressing over "freeloading" as a function of number of rewarded presses. Journal of Experimental Psychology, 1963, 65 , 451-454.

NEURINGER, A. J. Animals respond for food in the presence of free food. Science, 1969, 166, 399-401.

WINER, B. J. Statistical principles in experimental design. New York: McGraw-Hill, 1962. 